Supplementary Materials for

\title{
Three-dimensional printing of hierarchical porous architectures
}

Jen-Yu Huang, Hong Xu, Eliad Peretz, Dung-Yi Wu, Christopher K. Ober, Tobias Hanrath

*Correspondence to: th358@cornell.edu

This PDF file includes:

Table S1

Figs. S1 to S16

References 
The current state-of-the-art in additive manufacturing nanoparticle related inks.

Present 3D printing strategies involving nanoparticles have been demonstrated for different applications like conductive structures and ceramic (table S1). However, the lack of control at nanoscale impede the construction of complicated higher-order superstructures such as mesoporous material. Bridging the gap form fabricating nanoscale porous materials into 3D macroscopic architectures has presents a challenge with significant scientific and technological interest.

\begin{tabular}{|c|c|c|c|}
\hline Main compositions & Strategy & Usage & Ref. \\
\hline $\mathrm{Zr}_{6} \mathrm{O}_{4}(\mathrm{OH})_{4}-\mathrm{MAA}$ PLIC & Printable nanocluster & Porous material & This work \\
\hline $\mathrm{SiO}_{2}$ nanopowder + monomer & Add nanopowder & Glass & 1 \\
\hline $\mathrm{Ir}_{2} \mathrm{O}_{3}+$ monomer & Add nanopowder & $\begin{array}{l}\text { Ferromagnetic } \\
\text { structure }\end{array}$ & 2 \\
\hline $\mathrm{C}_{6} \mathrm{H}_{14} \mathrm{NiO}_{21}+$ monomer & $\begin{array}{c}\text { Add metal containing } \\
\text { solution }\end{array}$ & Metal & 3 \\
\hline $\mathrm{AgNO}_{3}+$ monomer & $\begin{array}{c}\text { Add metal containing } \\
\text { solution }\end{array}$ & Conductive structure & 4 \\
\hline $\mathrm{Si}\left(\mathrm{OC}_{2} \mathrm{H}_{5}\right)_{4}+$ monomer & Add inorganic solution & Hybrid material & 5 \\
\hline Si containing monomer & $\begin{array}{l}\text { Choose inorganic } \\
\text { containing resin }\end{array}$ & Ceramic & 6 \\
\hline $\begin{array}{l}\text { Si containing powder }+\mathrm{Si} \\
\text { containing monomer }\end{array}$ & $\begin{array}{c}\text { Add powder in inorganic } \\
\text { containing resin }\end{array}$ & Ceramic & 7 \\
\hline $\mathrm{Al}_{2} \mathrm{O}_{3}+$ monomer & Add powder & Hybrid material & 8 \\
\hline $\begin{array}{c}\mathrm{Pt} \& \mathrm{Ir}_{2} \mathrm{O}_{3} \text { nanoparticles }+ \\
\text { monomer }\end{array}$ & $\begin{array}{c}\text { Load nanoparticles after } \\
\text { printing }\end{array}$ & Micromachine & 9 \\
\hline
\end{tabular}


X-ray scattering structure analysis
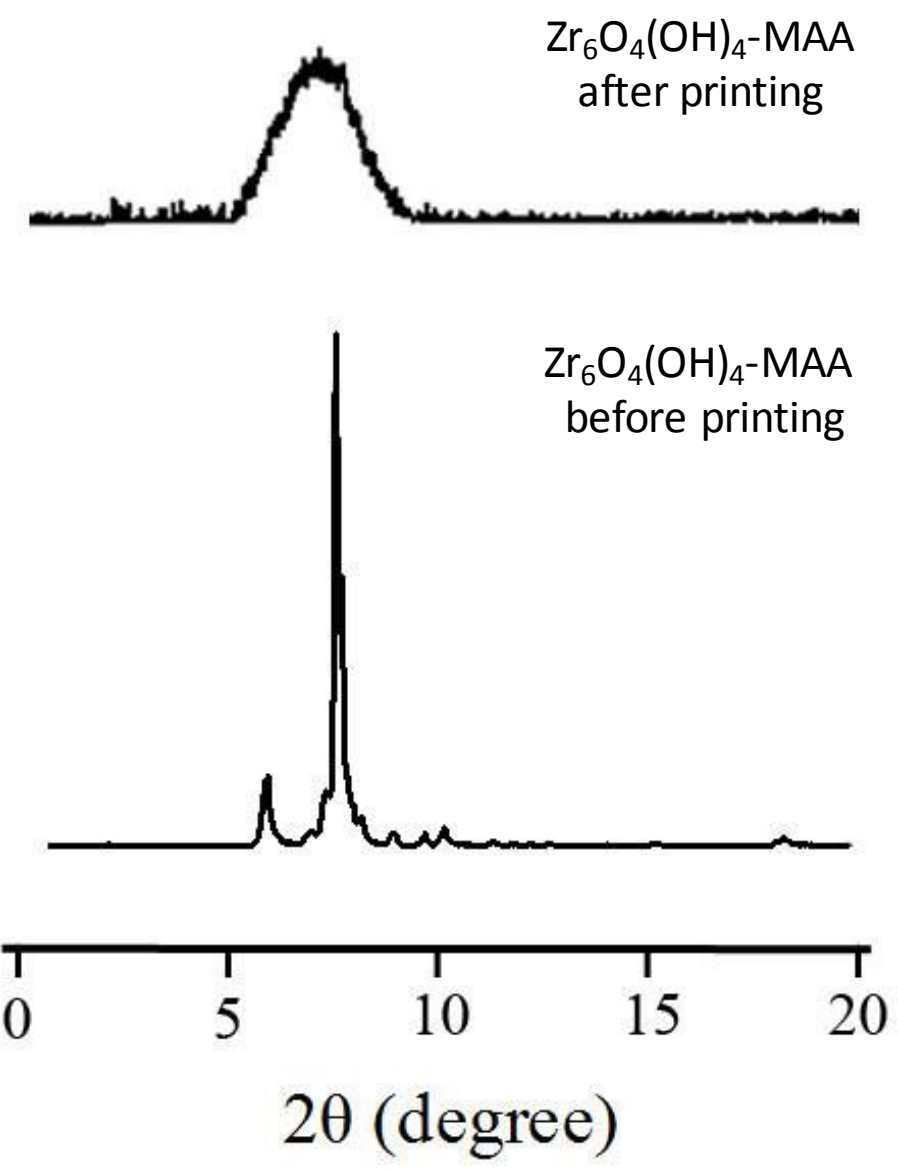

Fig. S1 PXRD of $\mathrm{Zr}_{6} \mathrm{O}_{4}(\mathrm{OH})_{4}$-MAA PLIC before and after printing. The synthesized zirconium methacrylate oxocluster possesses feature peaks at $5.9^{\circ}$ and $7.6^{\circ}$ being consistent to the reported ${ }^{10}$. More information of the crystal structure could be found in the references ${ }^{11,12}$. 


\section{Additional HRTEM analysis}
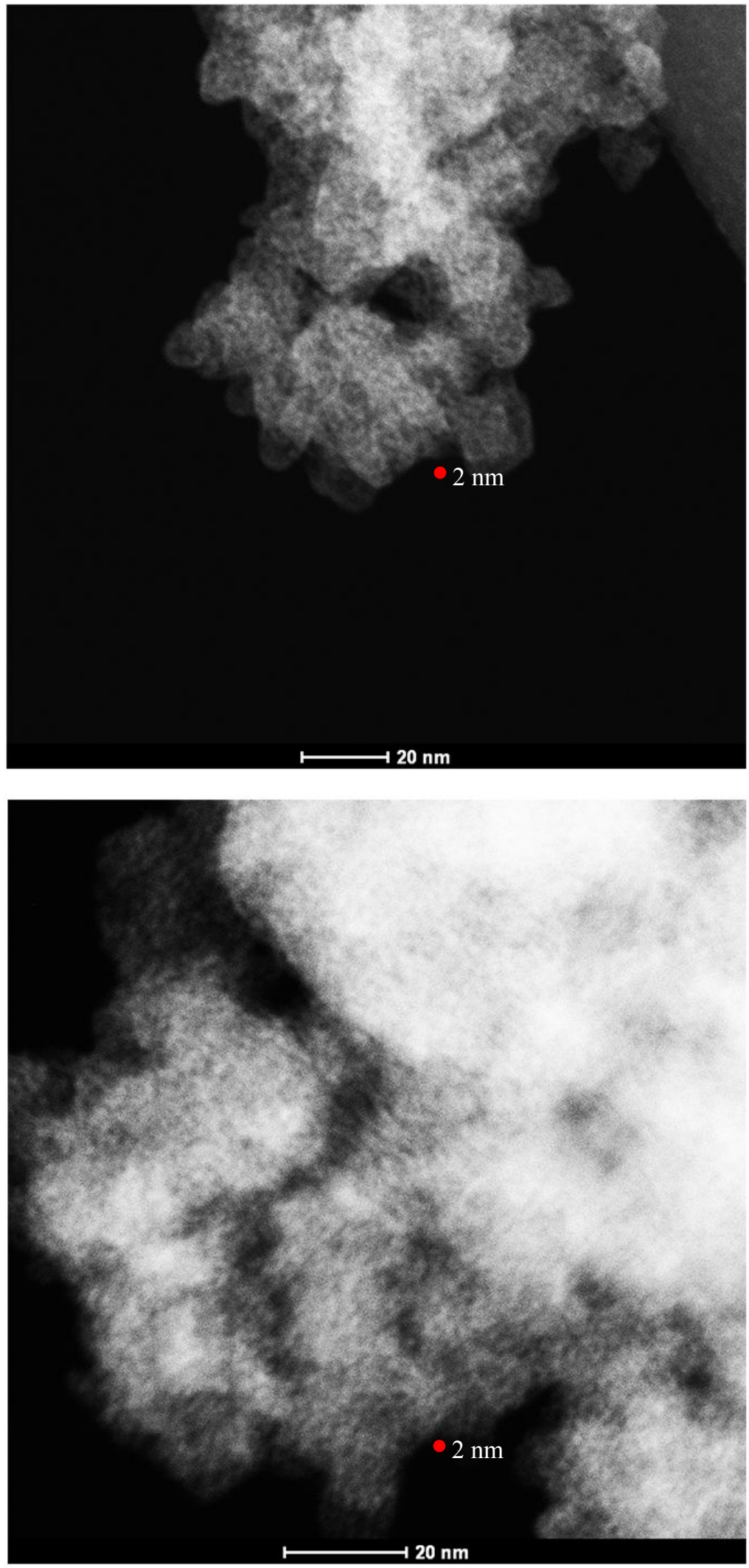

Fig. S2 STEM of 3D printed $\mathrm{Zr}_{6} \mathrm{O}_{4}(\mathrm{OH})_{4}$-MAA.

The building units are conserved after the reaction and form highly porous materials.

The red dot shows the scale of $2 \mathrm{~nm}$ as the comparison size with the building units. 


\section{PLIC fusion mechanism}

I Free radical polymerization (photopolymer)

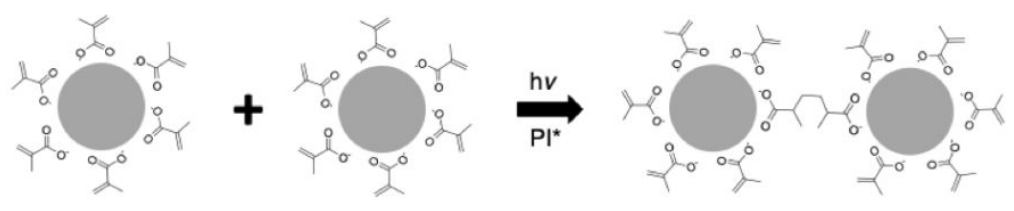

II UV ligand stripping (nanoparticle based ink in lithography)

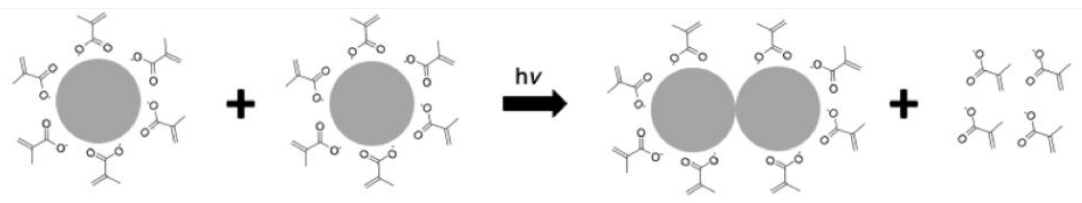

Fig. S3 Mechanisms for PLIC ink.

Figure S3 illustrates two possible mechanism by which PLIC ink is patterned during the processing. Mechanism $I$ is a normal route to initiate and propagate the polymerization for photopolymer used in the $3 \mathrm{D}$ printer ${ }^{13}$. Mechanism II is a proposed route for nanoparticle-based photoresist used in lithography ${ }^{14}$; the second mechanism involves photoinitiated detachment of surface-bound ligands which change the solubility of nanoparticles. In fact, the PLIC idea combine both the photoinitiator from mechanism I and similar nanoparticles from mechanism II . To better understand which mechanism is dominant, we have done control experiments and analyzed the mass distribution of products printed using PLIC inks. First, we couldn't get printed structures without adding photoinitiator, which suggests that mechanism I is dominant. Second, GPC analysis suggests that there are no fragments with mass larger than 1000 $\mathrm{Da}$, indicating no long polymer chain in the samples. Therefore, we propose that the mechanism $I$ is the main mechanism but some ligands may drop from the nanoparticles and participate in the propagate reaction when projecting 2D UV patterns. 


\section{FTIR analysis}
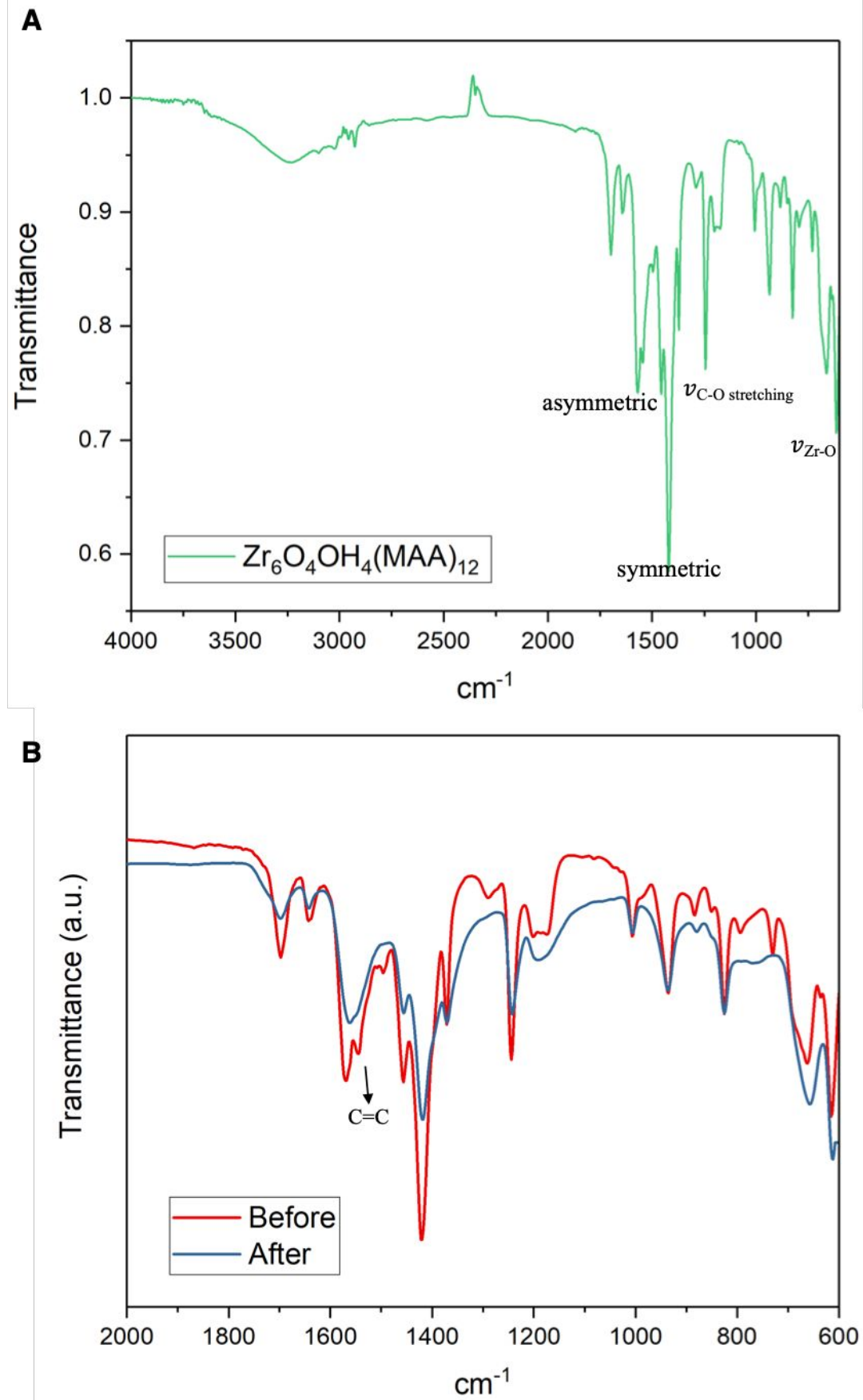

Fig. S4 FTIR of $\mathrm{Zr}_{6} \mathrm{O}_{4}(\mathrm{OH})_{4}$-MAA before and after printing.

(A) The three $\mathrm{COO}^{-}$vibrations and $\mathrm{Zr}-\mathrm{O}$ vibration are highlighted, showing coordinated methacrylic acid to the $\mathrm{Zr}$-oxide core ${ }^{15,16}$. Besides, the pattern is highly relevant to DAX \#10773 zirconium methacrylate. (B) The decreasing peak around $1600 \mathrm{~cm}^{-1}$ shows the consuming of $\mathrm{C}=\mathrm{C}$, which supports our proposed mechanism. 


\section{NMR analysis}

$\mathrm{OH} \sim 11.3$
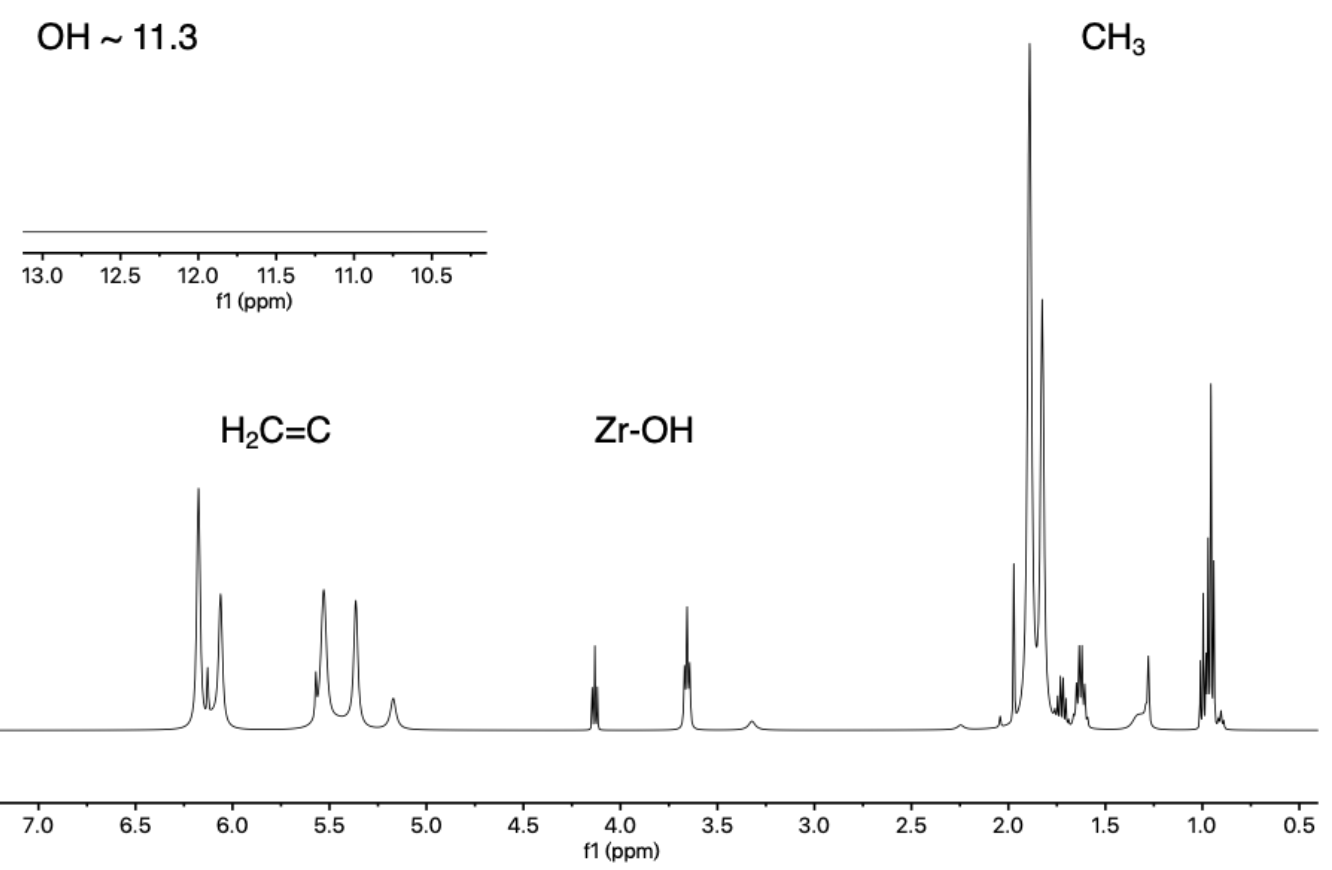

Fig. S5 NMR of $\mathrm{Zr}_{6} \mathrm{O}_{4}(\mathrm{OH})_{4}$-MAA PLIC.

The ${ }^{1} \mathrm{H}-\mathrm{NMR}$ spectrum of synthesized building unit was measured using $\mathrm{CDCl}_{3}$ as solvent. The signals match the reported spectrum of $\mathrm{Zr}_{6} \mathrm{O}_{4}(\mathrm{OH})_{4}(\text { methacrylate })_{12}{ }^{12}$. Signals at 6.14 and $5.55 \mathrm{ppm}$ are from the methacrylate ligands. We couldn't observe $\mathrm{OH}$ signal which should be around $11.3 \mathrm{ppm}$. 


\section{Dynamic Light Scattering (DLS)}

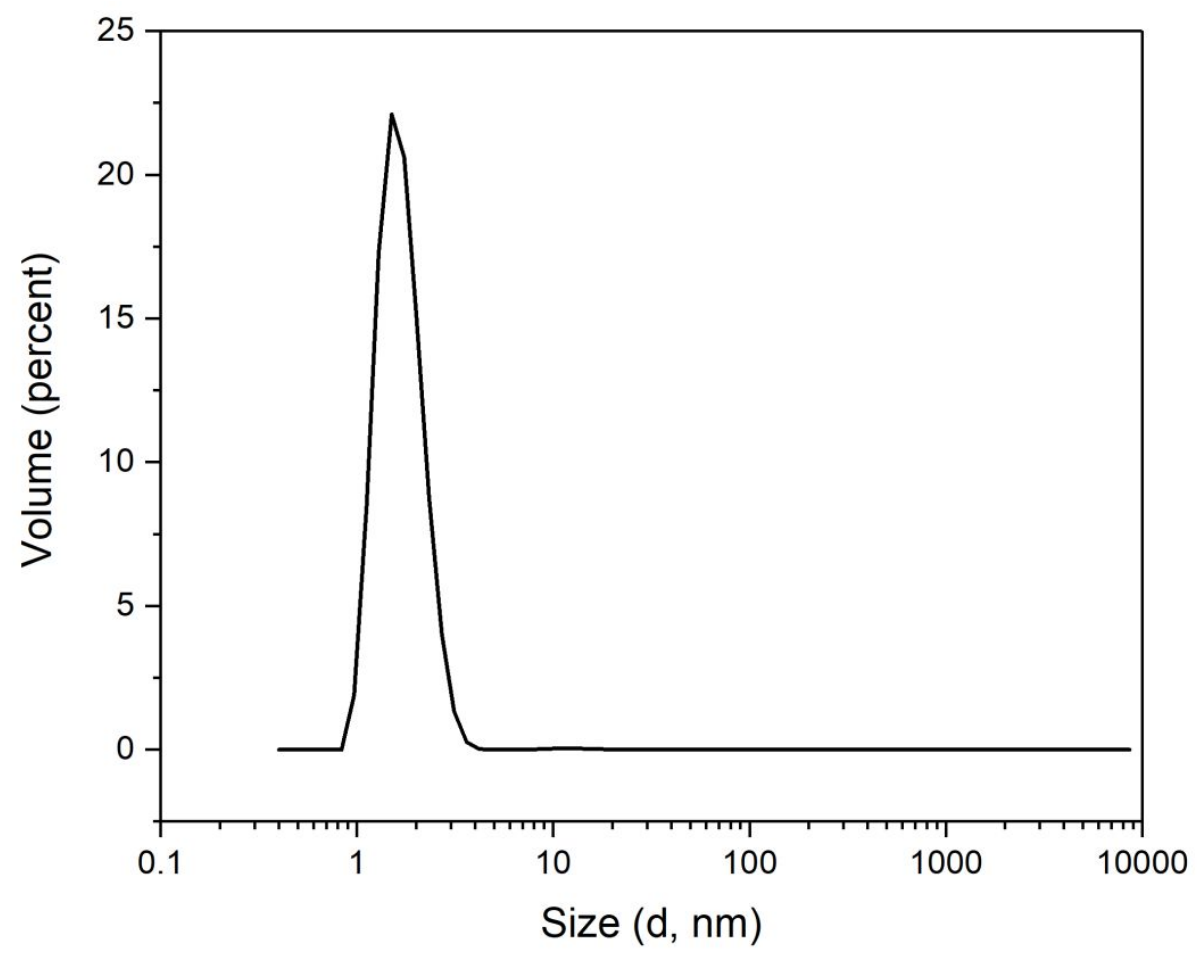

Fig. S6 DLS of $\mathrm{Zr}_{6} \mathrm{O}_{4}(\mathrm{OH})_{4}$-MAA PLIC measured in toluene.

The synthesized $\mathrm{Zr}_{6} \mathrm{O}_{4}(\mathrm{OH})_{4}$-MAA can be re-dispersed into proper solvent and form individual building units around $1.5 \mathrm{~nm}$. The clusters stay stable in the solvent. 


\section{PLIC resin solubility}

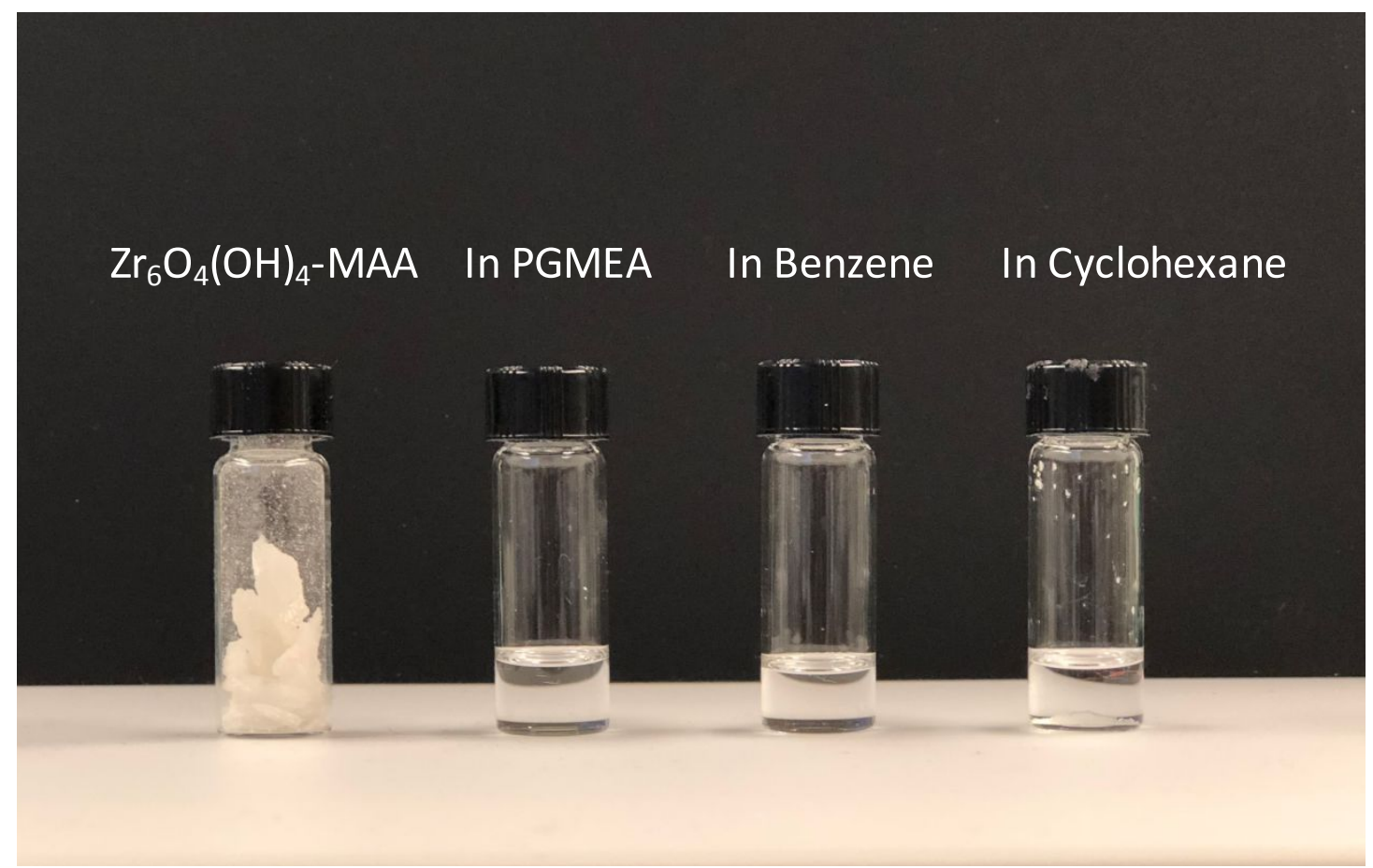

Fig. S7 Solvent comparison for ink formation.

$\mathrm{Zr}_{6} \mathrm{O}_{4}(\mathrm{OH})_{4}$-MAA crystal, solution of building units in PGMEA, benzene and cyclohexane are shown. For example, PGMEA and benzene are good solvents for the building units. However, building blocks are not soluble in solvent like cyclohexane, which makes assembly not printable. 


\section{Photo-rheometer analysis}
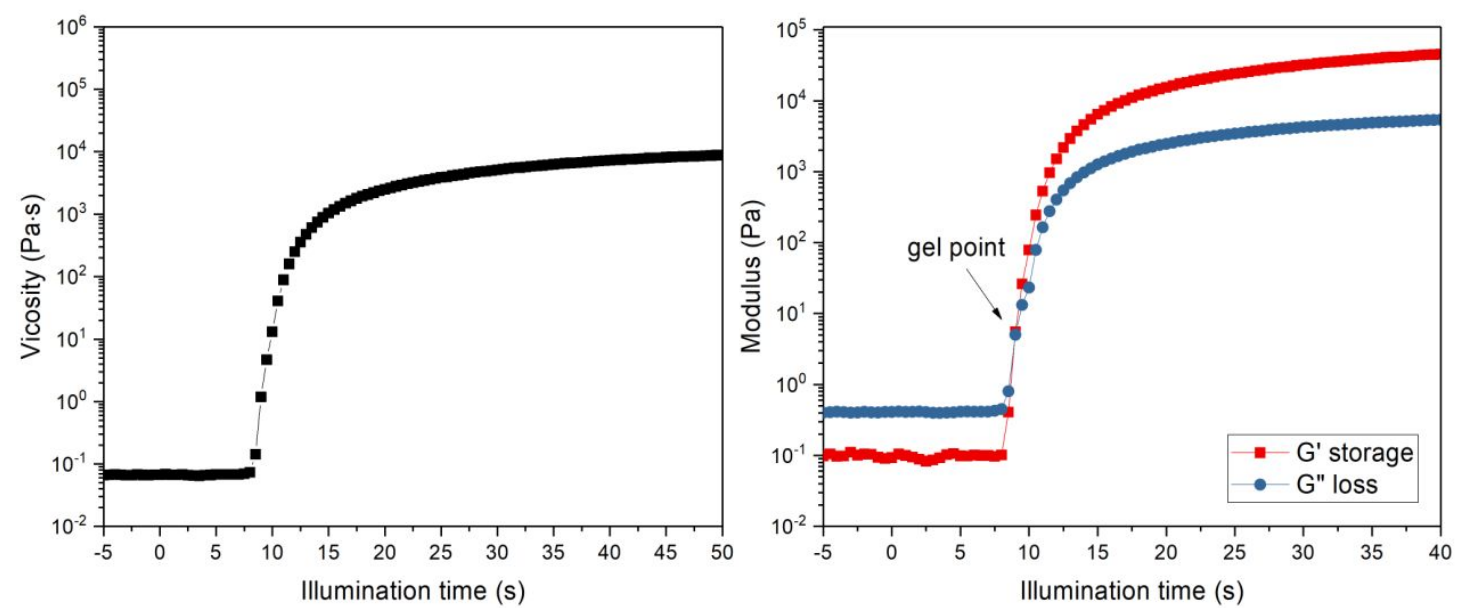

Fig. S8 Photo-rheometer for $\mathrm{Zr}_{6} \mathrm{O}_{4}(\mathrm{OH})_{4}$-MAA ink.

The speed of the ink is measured by photo-rheometer. Gel point, the crossing point of storage module and loss module, is often used to calculate the minimum dosage needed to turn inks from liquid phase into solid phase. The ink shows the speed to print 750 $\mu \mathrm{m}$ thick monoliths in 10 seconds. 


\section{Processing structure relationships - the effect of ink solvent}
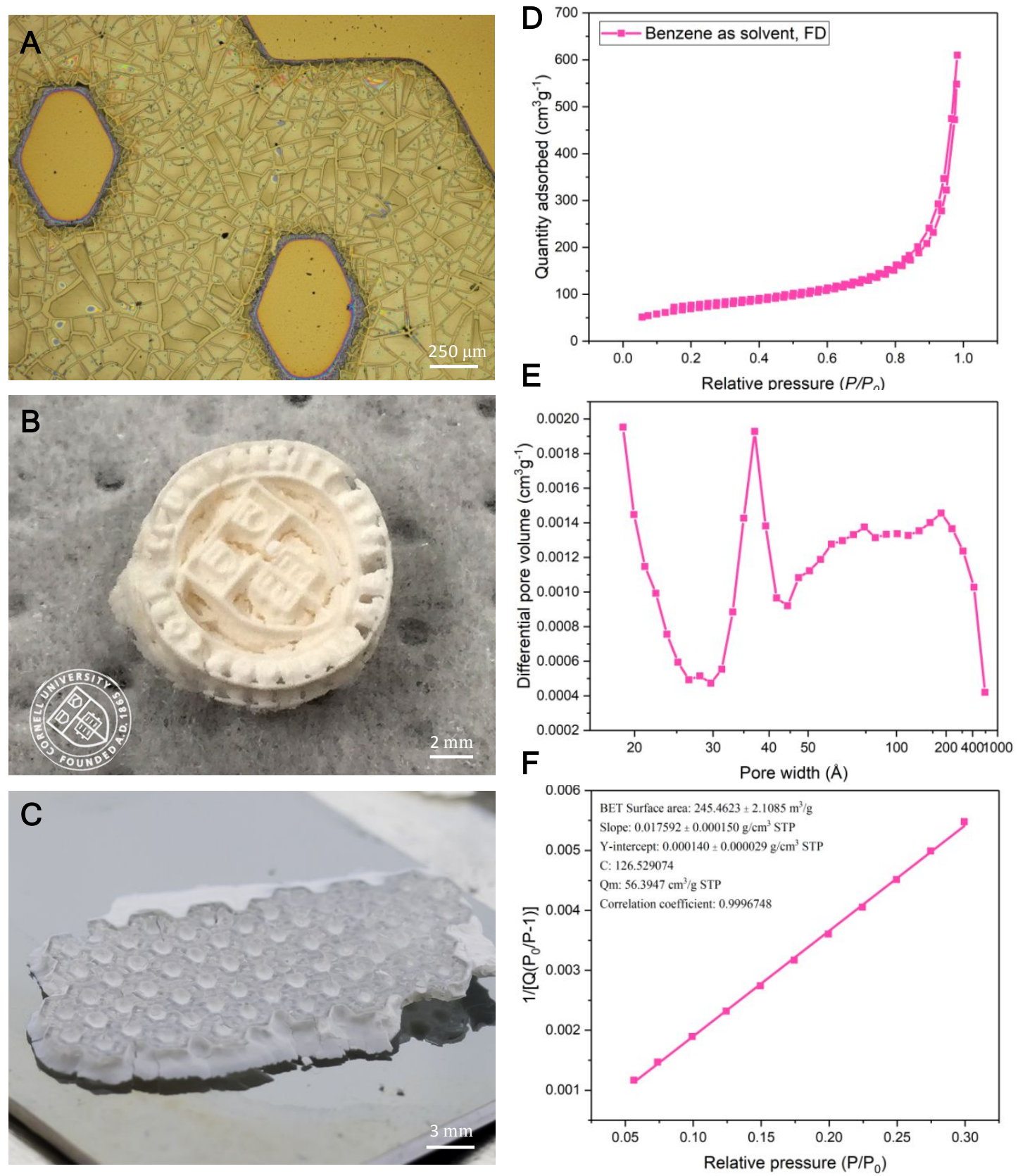

Fig. S9 The effect of solvent chosen and processing conditions.

Solvent chosen and processing are critical to conserve multi-level porous architectures. For example, shrinkage of the printed samples with direct drying make cracks in Fig. S8 (A). In addition, even the building units disperse well in the solvent like benzene, the printed samples exhibit more defects than using PGMEA as shown in Fig. S8 (B) with supercritical drying and (C) with freeze drying. Fig. S8 (D) to (F) demonstrates the surface area and pore-size distribution of Fig. S8 (C). The surface area decreases more than 50\% compared with Fig. 3 (A). (Logo used with permission. University logotype above is trademarked by Cornell University, Ithaca, New York.) 


\section{Additional nitrogen sorption and surface area consistency}
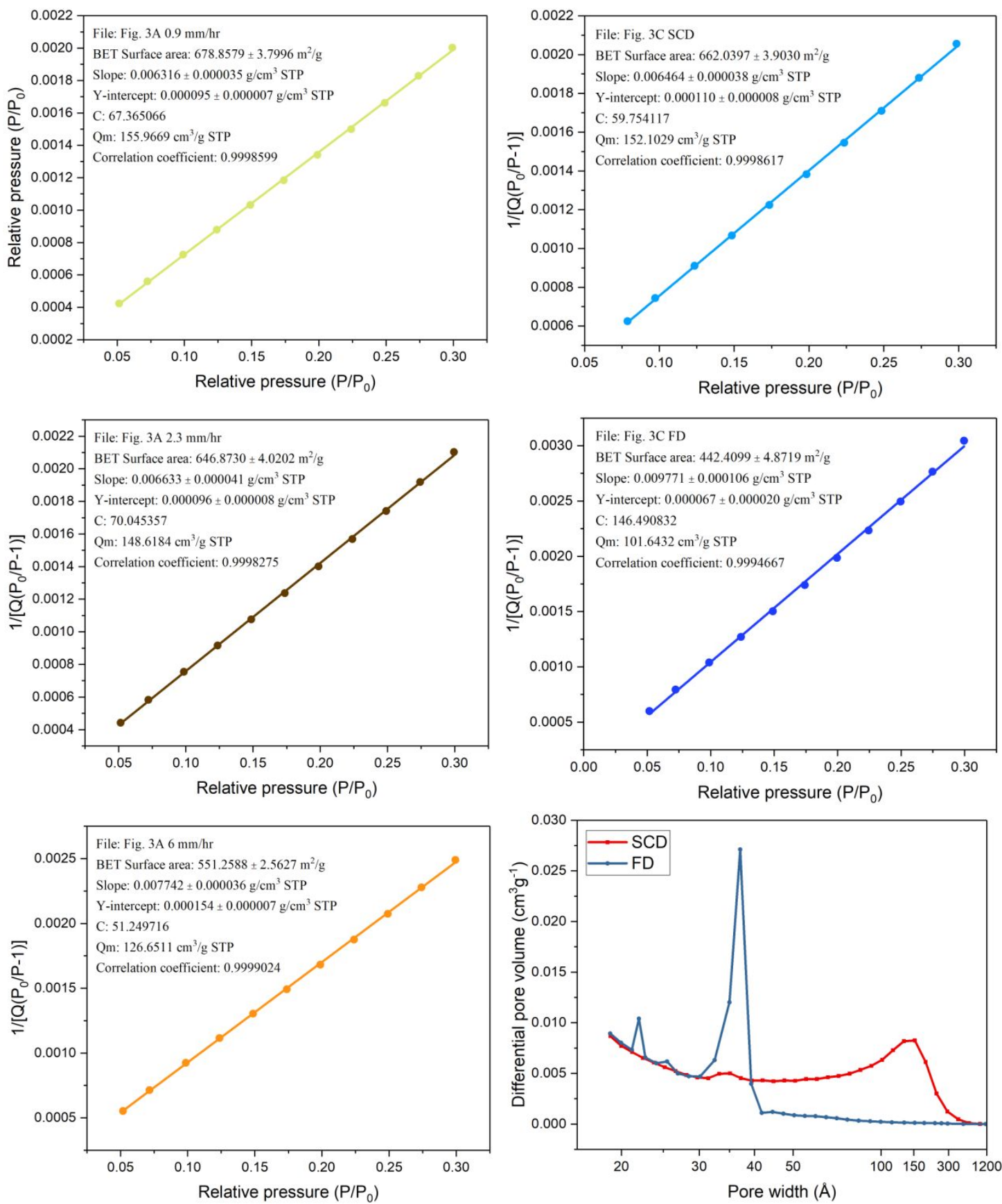

Fig. S10 BET consistency of different print speed and drying methods. 

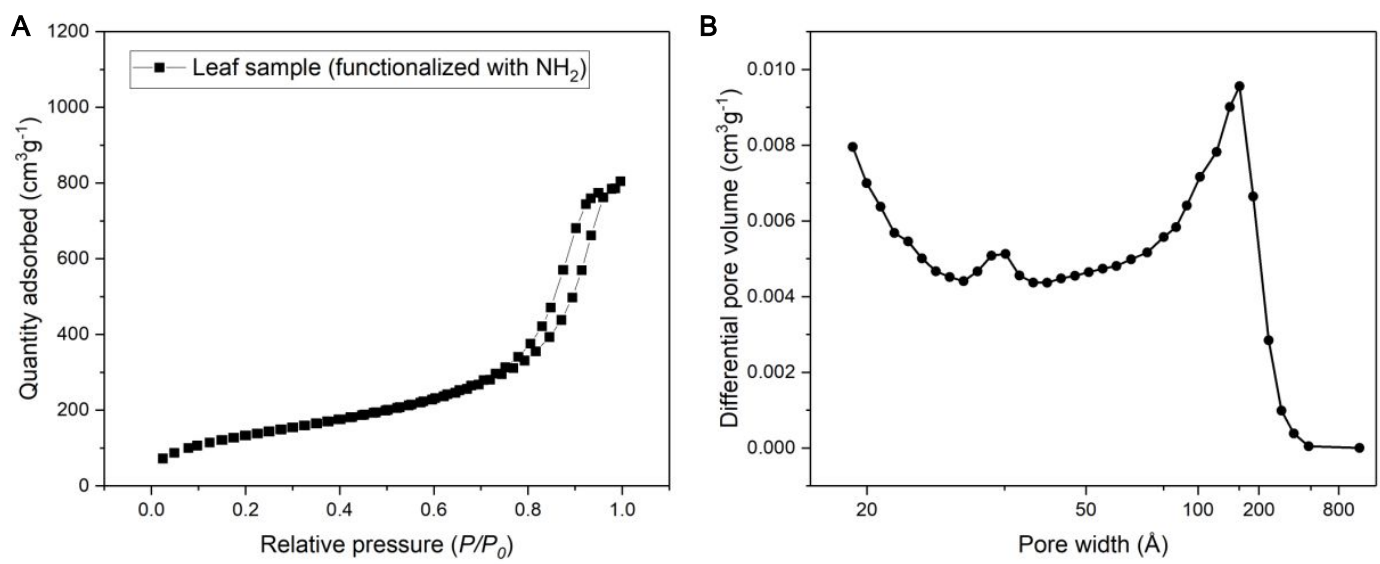

Fig. S11 Porosity characterization of Fig. 4 sample.

(A) The nitrogen sorption and (B) BJH pore size distribution of 3D printed leaf in Fig. 4. The BET surface area is around $496 \mathrm{~m}^{2} / \mathrm{g}$. The decrease of surface area may be caused by the filling of amine monomer or the degrade due to additional processing step. The pore size distribution is consistent to other samples. 


\section{Thermal stability analysis}
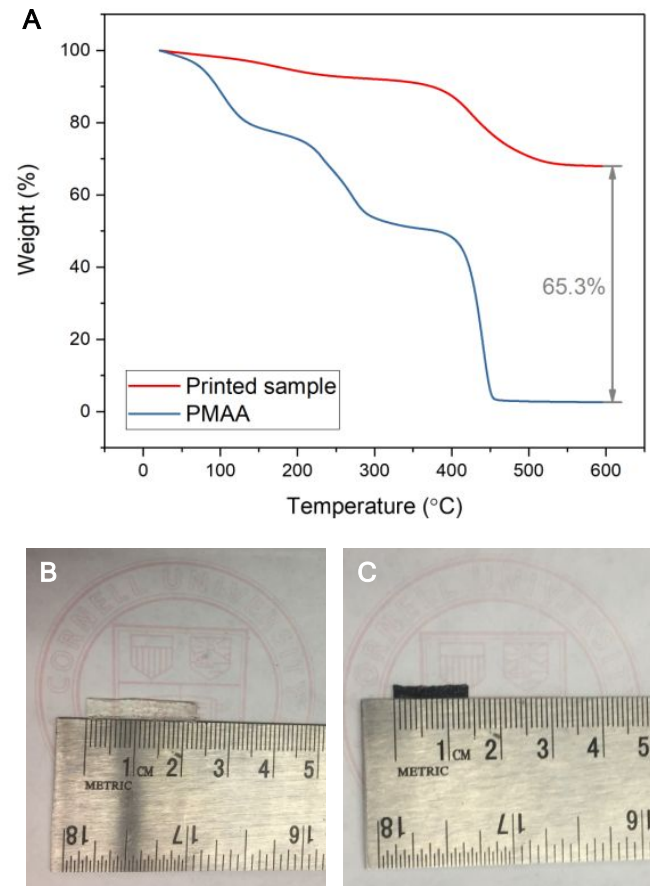

Fig. S12 TGA for thermal stability.

(A) TGA curves for printed sample with Zr-MAA PLIC ink. The significant weight loss starting from $400{ }^{\circ} \mathrm{C}$ is attributed to the decomposition of organic ligands, matching the loss to controlled PMAA. The printed sample (B) before and (C) after TGA analysis. The sample shrinks around $17 \%$ in length. (Logo used with permission. University logotype above is trademarked by Cornell University, Ithaca, New York.)

\section{Resolution of PLIC ink}
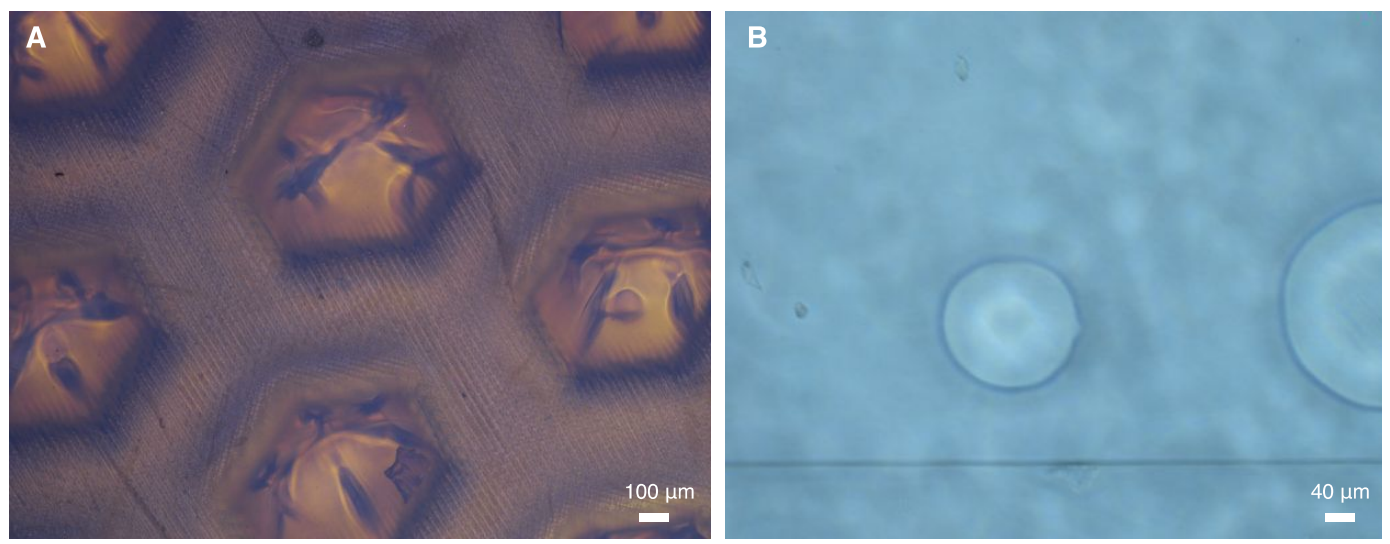

Fig. S13 Resolution discussion of PLIC ink.

The pattern of pixels from the light source could be observed in (A) from the overexposed sample. The brick-liked patterns possess the width around $40 \mu \mathrm{m}$ being 
relevant to the reported $50 \mu \mathrm{m}$ resolution. (B) A printed circle around $170 \mu \mathrm{m}$ with sharp edges shows the resolution is not affected too much by the PLIC ink.

\section{Control experiments of PMAA}
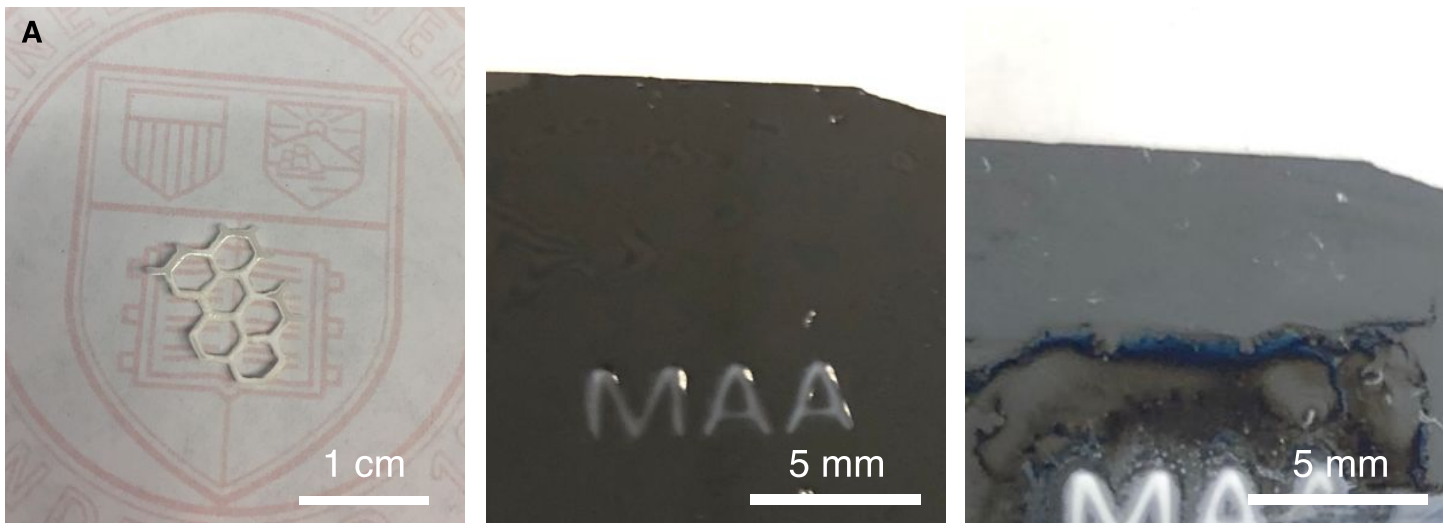

Fig. S14 Photo-radical polymerized methacrylic acid.

Comparison of polymerized methacrylic acid without PLIC were made. (A) shows the sample polymerized from $1 \mathrm{ml}$ of methacrylic acid with $20 \mathrm{mg}$ of PI. The sample is rigid and holdable. (B) and (C) show the sample polymerized from $63 \mathrm{mg}$ of methacrylic acid (60\% of $150 \mathrm{mg}$ PLIC), $1 \mathrm{mg}$ of photoinitiator in $1 \mathrm{ml}$ of PGMEA by reacting for 5 mins before and after washing, respectively. The sample is relatively fragile and easily damaged compared with the samples from the PLIC ink (Fig. S13 A \& B), supporting the nanocluster plays an important role in printing. (Logo used with permission. University logotype above is trademarked by Cornell University, Ithaca, New York.) 


\section{Degree of photopolymerization}

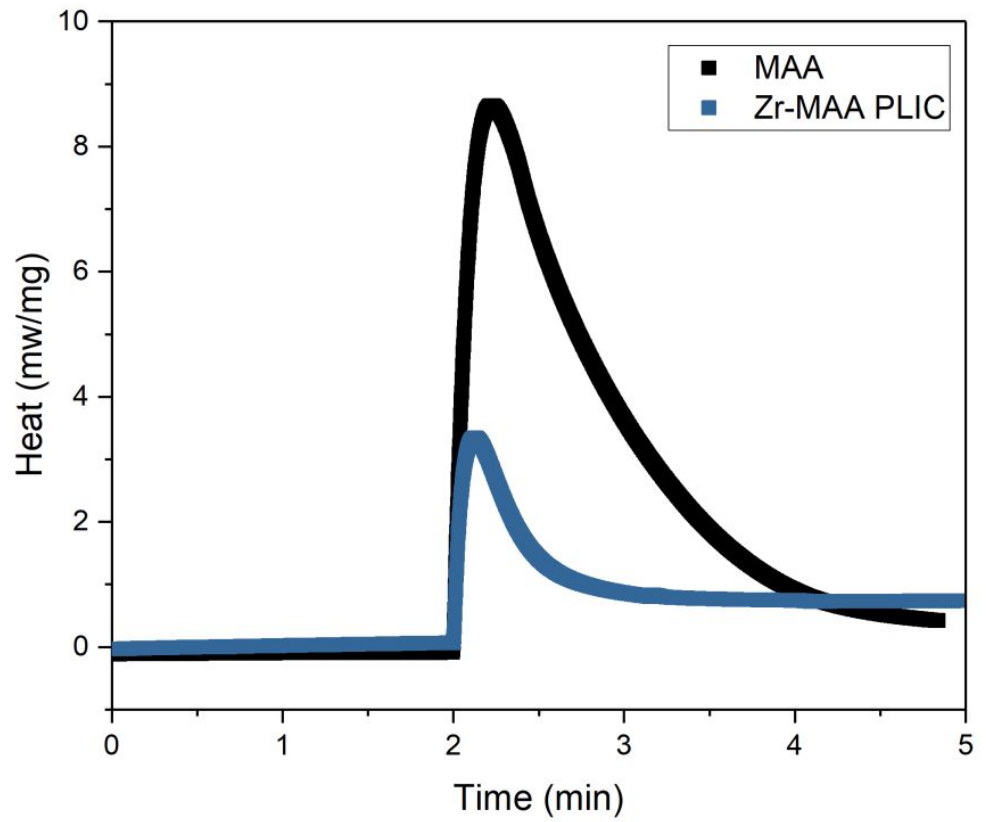

Fig. S15 Photo-Differential Scanning Calorimetry (photo-DSC).

Degree of conversion is measured by photo-DSC to evaluate how many ligands in the Zr-MAA PLIC building blocks are reacted during the photopolymerization. The reaction heat, integral of the peak, was directly related to vinyl group consumed in the system by the following equation:

$$
\alpha=\frac{\Delta H_{t}}{\Delta H_{0}}
$$

where $\Delta H_{t}$ is the reaction heat evolved at time $\mathrm{t}$ and $\Delta H_{0}$ is the heat for complete conversion ${ }^{17}$. First, the $\Delta H_{0}$ of methacrylic acid is measured and consistent to reported number ${ }^{18}$. The $\alpha$ of $\mathrm{Zr}$-MAA PLIC is 0.28 supporting around $28.3 \%$ of ligands are consumed during the $3 \mathrm{D}$ printing process. (Note: the unit in the figure is $\mathrm{mW} / \mathrm{mg}$ of $\mathrm{Zr}$ MAA, so the integral area is multiplied by 1.67 to include that only $60 \mathrm{wt} \%$ is methacrylic acid in the building block for the calculation of $\alpha$.) 

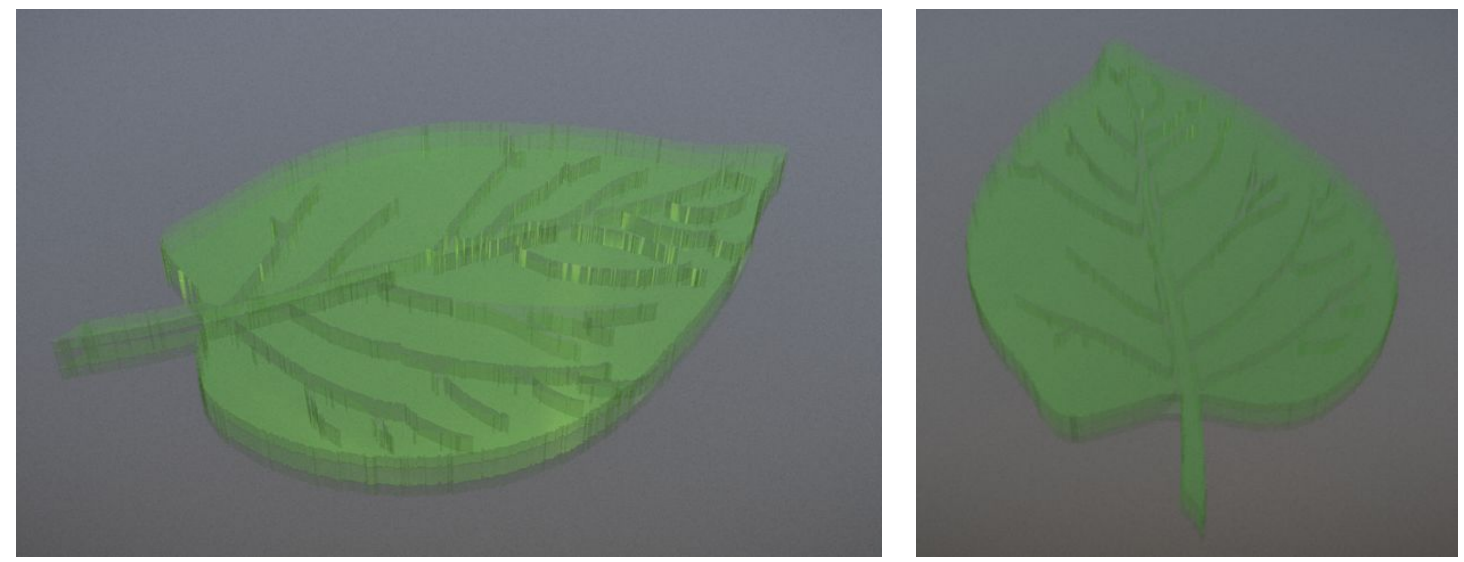

Fig. S16 CAD model of artificial leaf.

\section{References}

(1) Kotz, F.; Arnold, K.; Bauer, W.; Schild, D.; Keller, N.; Sachsenheimer, K.; Nargang, T. M.; Richter, C.; Helmer, D.; Rapp, B. E. Three-Dimensional Printing of Transparent Fused Silica Glass. Nature 2017, 544, 337-339.

(2) Credi, C.; Fiorese, A.; Tironi, M.; Bernasconi, R.; Magagnin, L.; Levi, M.; Turri, S. 3D Printing of Cantilever-Type Microstructures by Stereolithography of Ferromagnetic Photopolymers. ACS Applied Materials \& Interfaces 2016, $8,26332-26342$.

(3) Vyatskikh, A.; Delalande, S.; Kudo, A.; Zhang, X.; Portela, C. M.; Greer, J. R. Additive Manufacturing of 3D Nano-Architected Metals. Nature Communications 2018, 9, 1-8.

(4) Fantino, E.; Chiappone, A.; Roppolo, I.; Manfredi, D.; Bongiovanni, R.; Pirri, C. F.; Calignano, F. 3D Printing of Conductive Complex Structures with in Situ Generation of Silver Nanoparticles. Adv. Mater. 2016, 28, 3712-3717.

(5) Chiappone, A.; Fantino, E.; Roppolo, I.; Lorusso, M.; Manfredi, D.; Fino, P.; Pirri, C. F.; Calignano, F. 3D Printed PEG-Based Hybrid Nanocomposites Obtained by Sol-Gel Technique. ACS Applied Materials \& Interfaces 2016, 8, $5627-5633$.

(6) Eckel, Z. C.; Zhou, C.; Martin, J. H.; Jacobsen, A. J.; Carter, W. B.; Schaedler, T. A. Additive Manufacturing of Polymer-Derived Ceramics. Science 2015, $351,58-62$.

(7) Zanchetta, E.; Cattaldo, M.; Franchin, G.; Schwentenwein, M.; Homa, J.; Brusatin, G.; Colombo, P. Stereolithography of SiOC Ceramic Microcomponents. Adv. Mater. 2015, 28, 370-376. 
(8) Martin, J. J.; Fiore, B. E.; Erb, R. M. Designing Bioinspired Composite Reinforcement Architectures via 3D Magnetic Printing. Nature Communications 2015, 6, 1-7.

(9) Zhu, W.; Li, J.; Leong, Y. J.; Rozen, I.; Qu, X.; Dong, R.; Wu, Z.; Gao, W.; Chung, P. H.; Wang, J.; et al. 3D-Printed Artificial Microfish. Adv. Mater. 2015, 27, 4411-4417.

(10) Užarević, K.; Wang, T. C.; Moon, S.-Y.; Fidelli, A. M.; Hupp, J. T.; Farha, O. K.; Friščić, T. Mechanochemical and Solvent-Free Assembly of ZirconiumBased Metal-Organic Frameworks. Chemical Communications 2016, 52, 2133-2136.

(11) Kickelbick, G.; Schubert, U. Oxozirconium Methacrylate Clusters: $\mathrm{Zr}_{6}(\mathrm{OH})_{4} \mathrm{O}_{4}(\mathrm{OMc})_{12}$ and $\mathrm{Zr}_{4} \mathrm{O}_{2}(\mathrm{OMc})_{12}(\mathrm{OMc}=$ Methacrylate $)$. Chemische Berichte 1997, 130, 473-478.

(12) Kogler, F. R.; Jupa, M.; Puchberger, M.; Schubert, U. Control of the Ratio of Functional and Non-Functional Ligands in Clusters of the Type $\mathrm{Zr}_{6} \mathrm{O}_{4}(\mathrm{OH})$ ${ }_{4}(\text { Carboxylate })_{12}$ for Their Use as Building Blocks for Inorganic-Organic Hybrid Polymers. J. Mater. Chem. 2004, 14, 3133-3138.

(13) Tumbleston, J. R.; Shirvanyants, D. Continuous Liquid Interface Production of 3D Objects. Science 2015, 347, 1346-1349.

(14) Kryask, M.; Trikeriotis, M.; Ouyang, C.; Chakrabarty, S.; Giannelis, E. P.; Ober, C. K. Nanoparticle Photoresists: Ligand Exchange as a New, Sensitive EUV Patterning Mechanism TI . Journal of Photopolymer Science and Technology 2013, 26, 659-664.

(15) Mos, R. B.; Nasui, M.; Petrisor, T., Jr; Gabor, M. S.; Varga, R. A.; Ciontea, L. Synthesis, Crystal Structure and Thermal Decomposition of $\mathrm{Zr}_{6} \mathrm{O}_{4}(\mathrm{OH})_{4}(\mathrm{CH} 3 \mathrm{CH} 2 \mathrm{COO})_{12}$. Journal of Analytical and Applied Pyrolysis 2012, 97, 137-142.

(16) Kosma, V.; Kasahara, K.; Xu, H.; Odent, J.; Ober, C. K. Elucidating the Patterning Mechanism of Zirconium-Based Hybrid Photoresists. $J$. Micro/Nanolith. MEMS MOEMS 2018, 16, 1-8.

(17) Palanisamy, A.; Rao, B. S. Photo-DSC and Dynamic Mechanical Studies on UV Curable Compositions Containing Diacrylate of Ricinoleic Acid Amide Derived From Castor Oil. Progress in Organic Coatings 2007, 60, 161-169.

(18) Liska, R.; Schwager, F.; Maier, C.; Cano-Vives, R.; Stampfl, J. Water-Soluble Photopolymers for Rapid Prototyping of Cellular Materials. J. Appl. Polym. Sci. 
2005, 97, 2286-2298. 